\title{
Utility of diffusion weighted imaging with the quantitative apparent diffusion coefficient in diagnosing residual or recurrent hepatocellular carcinoma after transarterial chemoembolization: a meta- analysis
}

Zhao Liu' ${ }^{1,2}$, Jin-Ming Fan ${ }^{1,2}$, Chen He ${ }^{1,2}$, Zhi-Fan Li ${ }^{1,2}$, Yong-Sheng $\mathrm{Xu}^{2}$, Zhao Li ${ }^{1,2}$, Hai-Feng Liu ${ }^{3^{*}}$ and Jun-Qiang Lei ${ }^{2}$

\begin{abstract}
Background: Accurate and early diagnosis of residual tumors or intrahepatic recurrences after TACE is critically needed for determining the success of treatments and for guiding subsequent therapeutic planning. This metaanalysis was performed to assess the efficacy of diffusion weighted imaging (DWI) with the quantitative apparent diffusion coefficient (ADC) value in diagnosing residual or recurrent hepatocellular carcinoma after transarterial chemoembolization (TACE).
\end{abstract}

Materials and methods: A comprehensive literature search of PubMed, Embase, Web of Science, Scopus and the Cochrane Library database, from inception to July 2019, was conducted to select original studies on diagnosing residual or recurrent HCCs after TACE using DWI sequence with its ADC value. Two researchers independently chose study, extracted data, conducted meta-analysis, and evaluated methodological quality according to Quality Assessment of Diagnostic Accuracy Studies-2 (QUADAS-2) tool.

Results: Twelve studies comprising 624 patients and 712 tumors were finally included. The pooled sensitivity, specificity and AUC value of DWI in diagnosing residual or recurrent HCCs after TACE were 85\% (95\%Cl: 74-92\%), 83\% (95\%Cl: 75-88\%) and 0.90 (95\%Cl: 0.87-0.92), respectively. Residual or recurrent HCCs have significantly lower ADC value than necrotic tumors (MD $=-0.48,95 \% \mathrm{Cl}:-0.69 \sim-0.27, P<0.01)$.

Conclusion: This study demonstrated that DWI performed better in diagnosing residual or recurrent HCCs after TACE, and ADC value may serve as alternatives for further evaluation of residual or recurrent leisions in HCC patients after TACE.

Keywords: Diffusion weighted imaging (DWI), Apparent diffusion coefficient (ADC), Hepatocellular carcinoma (HCC), Transarterial chemoembolization (TACE), Meta-analysis

\footnotetext{
* Correspondence: liuhfyx@163.com

${ }^{3}$ Department of Radiology, Third Affiliated Hospital of Soochow University \&

Changzhou First People's Hospital, No.185, Juqian Street, Tianning District,

Changzhou 213003, Jiangsu, China

Full list of author information is available at the end of the article
}

(c) The Author(s). 2020 Open Access This article is distributed under the terms of the Creative Commons Attribution 4.0 International License (http://creativecommons.org/licenses/by/4.0/), which permits unrestricted use, distribution, and reproduction in any medium, provided you give appropriate credit to the original author(s) and the source, provide a link to the Creative Commons license, and indicate if changes were made. The Creative Commons Public Domain Dedication waiver (http://creativecommons.org/publicdomain/zero/1.0/) applies to the data made available in this article, unless otherwise stated. 


\section{Introduction}

Hepatocellular carcinoma (HCC) is one of the most malignant tumors, with serious threats to human life and health, and it is estimated to be the fourth major factor of cancer death in the worldwide population [1]. However, only approximately $20 \%$ of patients with HCC are suitable for surgical resection or liver transplantation, mainly because the tumors are often diagnosed at an intermediate to advanced stage, and the associated liver cirrhosis is too far developed to permit tumor resection or liver transplantation to be endured [2, 3].

As a first-line and curative therapy, transarterial chemoembolization (TACE) operates by injecting chemotherapeutic drugs at the HCC site while impeding blood supply to the tumor. In previous studies, TACE has been proven to be an efficient bridge therapy for patients waiting for liver transplantation and can improve survival prognosis in patients with inoperable $\mathrm{HCC}[4,5]$. However, the rate of recurrent $\mathrm{HCC}$ after TACE is relatively high, with reported 12-month recurrence rates of $78 \%$ [6]. Therefore, the accurate and early diagnosis of residual tumors or intrahepatic recurrences after TACE is critically needed for determining the success of treatments and for guiding subsequent therapeutic planning.

By detecting water diffusion indirectly, diffusion weighted imaging (DWI) provides information regarding tissue cellularity and cell membrane integrity, and its quantitative value of the apparent diffusion coefficient (ADC) is highly associated with tumor cellularity [7, 8], indicating that DWI and ADC values may be potentially used to diagnose and differentiate residual or recurrent HCCs after TACE. Moreover, DWI and ADC values are of great importance in guiding the post-TACE treatment of patients with HCC. However, the accuracy of DWI and the quantitative $\mathrm{ADC}$ value for diagnosing residual or recurrent HCCs has shown conflicting results in an increasingly large number of clinical trials, mainly because different diagnostic accuracies associated with DWI and ADC values have been reported [9-20]. Therefore, based on the currently available published articles on DWI and the ADC value in detecting residual or recurrent HCCs after TACE, this meta-analysis was performed to provide evidence-based conclusions for imaging diagnostics.

\section{Materials and methods Literature search}

According to the Preferred Reporting Items for Systematic reviews and Meta-Analyses (PRISMA) guidelines [21], a comprehensive literature search in PubMed, Embase, Web of Science, Scopus and the Cochrane library database was performed to select original studies, from inception to July 2019, that evaluated the accuracy of DWI and the quantitative $\mathrm{ADC}$ value in diagnosing residual or recurrent $\mathrm{HCCs}$ after TACE. Medical subject heading words and free words were used conjunctly and were as follows: (1) "Diffusion weighted imaging" or "DWI"; and (2) "transarterial chemoembolization" or "transcatheter arterial chemoembolization" or "TACE". In addition, a manual search was performed of the identified review articles and included the study references to acquire available studies and to minimize the potential publication bias.

\section{Selection of articles \\ Inclusion criteria}

(1) DWI and the calculated ADC values were used as diagnostic indices for detecting residual or recurrent HCCs after TACE. (2) Pathology and/or digital subtraction angiography (DSA) and/or follow-up clinical results served as the reference standard [22]. (3) The two-bytwo table, including the true-positive (TP), false-positive (FP), false-negative (FN) and true-negative (TN) values, could be extracted or calculated. (4) More than 10 patients were included in the study. (5) When the data were published repeatedly, the latest study with detailed information was included. (6) The study was published in English.

\section{Exclusion criteria}

(1) Surgical resection and any other therapies besides TACE were applied to treat HCC. (2) The two-by-two table of DWI alone could not be acquired when DWI was used in conjunction with other MRI images; these studies were also excluded. (3) Review articles, case reports, animal studies, and editorial comments were excluded. (4) Conferences abstracts were also excluded, as their conclusions might not be up to date.

\section{Data extraction and quality assessment}

Two researchers (ZL and HFL) independently extracted the study data and evaluated the methodological quality using the Quality Assessment of Diagnostic Accuracy Studies-2 (QUADAS-2) tool [23], and any disagreements were solved through discussion until consensus was reached. A predefined Excel file was adopted to extract study data, including first author name, publication year, country, study design type (prospective or retrospective), baseline information of involved patients (number, mean age, gender, the number of lesions), time interval between TACE and DWI examination, blinding method application, reference standard, DWI protocol (field strength, b value, ADC cut-off value), and threshold method used (visual diagnosis or ADC measurement). Additionally, two-by-two table values were extracted from all included studies. The quality was assessed via the evaluation of risk bias in four domains (patient selection, index test, reference standard, and flow and timing) and clinical applicability in three domains (patient 
selection, index test and reference standard) of the study characteristics. Each domain was scored as high, low, or unclear.

\section{Data synthesis and statistical analysis}

Data synthesis and statistical analysis were performed using STATA (version 12.0, StataCorp, USA) and Review Manager software (version 5.3, the Cochrane Collaboration, 2014). To present the study characteristics of DWI in diagnosing residual or recurrent HCCs after TACE suitably, data synthesis was performed by the METANDI module and hierarchical logistic regression modeling in STATA software. The Spearman correlation coefficient was calculated to test the threshold, and a $P$-value less than 0.05 indicated the threshold effect. A chi-squared test was performed to measure the heterogeneity degree of the enrolled studies, and the degree was considered low for Isquared $\left(I^{2}\right)=25$ to $49 \%$, moderate for $I^{2}=50$ to $74 \%$, and high for $I^{2}>75 \%$.

The pooled sensitivity (SEN), specificity (SPE), positive likelihood ratio (PLR) and negative likelihood ratio (NLR) with their 95\% confidence intervals (CIs) were computed from the two-by-two table data. Then, the receiver operator characteristics (ROC) curve and area under the ROC curve (AUC) were computed to evaluate the value of DWI in diagnosing residual or recurrent HCCs after TACE, and the value was considered good for AUC values $>0.9$ and medium for AUC values from 0.7 to 0.9. Moreover, the ADC values of the residual or recurrent $\mathrm{HCC}$ group and the necrotic lesion group were compared and pooled as the mean difference (MD) with a random-effects model to incorporate expected heterogeneity. Additionally, possible factors, including study design type (retrospective or prospective), b value $(<800$ or $\geq 800)$ and threshold method (visual analysis or $\mathrm{ADC}$ measurement), that may lead to heterogeneity were analyzed through subgroup analysis. Moreover, the reliability and stability of this study were evaluated through sensitivity analysis. Last, Deeks' funnel plot with the linear regression of log odds ratios on the inverse root of effective sample sizes was performed to test for publication bias: a $P$-value $<0.05$ was representative of publication bias.

\section{Result}

\section{Study selection and description}

Figure 1 demonstrates a detailed flowchart of the study selection process. The electronic search combined with the manual search initially yielded 2210 potential literature references, and this number was reduced to 1356 after removing 854 duplicated references by Endnote X7 software. Upon reading the titles and abstracts, only 97 references were retrieved for further inspection. After full text review, a total of 12 studies [9-20], comprising 624 patients and 712 tumors evaluated by DWI, were finally included. The baseline information extracted from each study is presented in Table 1 .

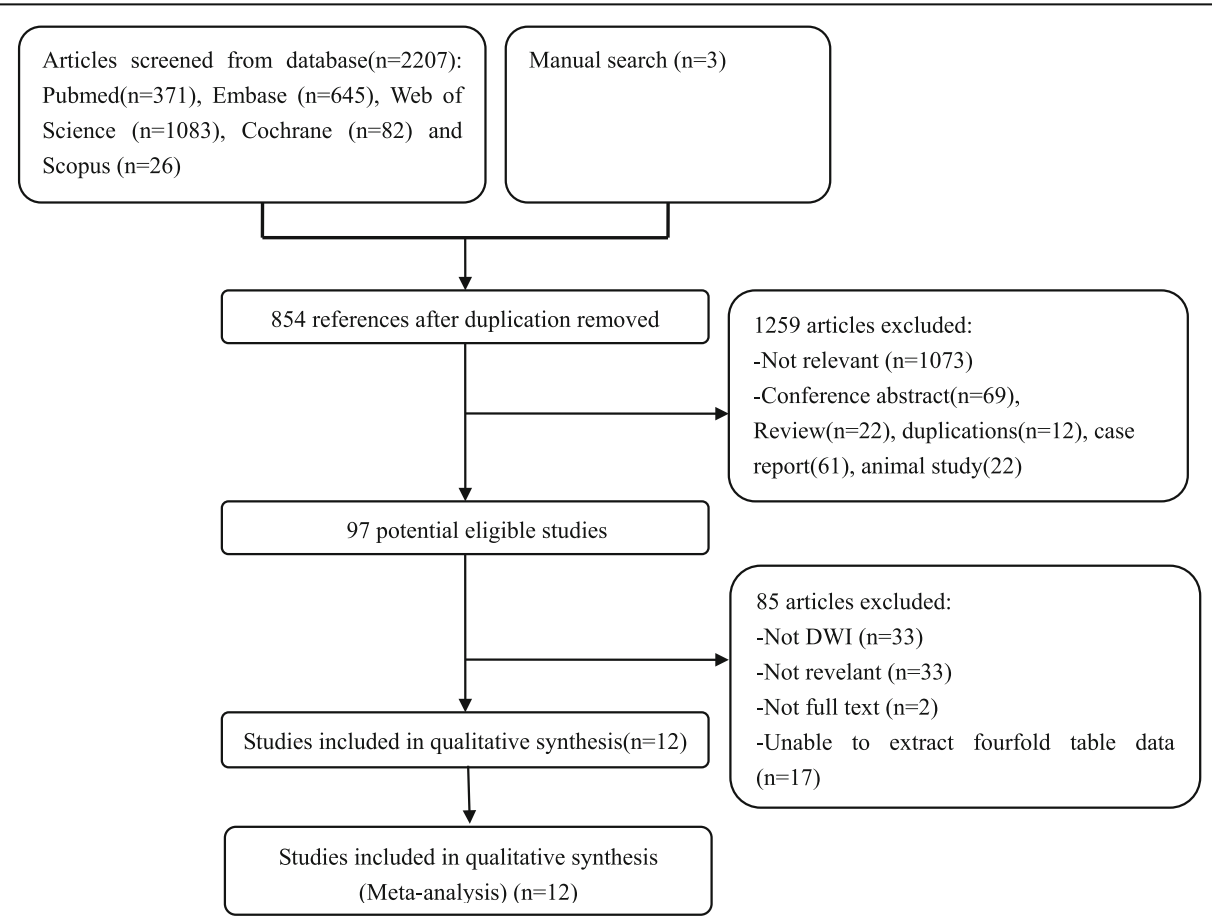

Fig. 1 The flowchart of the study selection process 
Table. 1 Baseine characteristics of included studes

\begin{tabular}{|c|c|c|c|c|c|c|c|c|c|c|c|c|c|c|}
\hline Author & Year & Country & Design & $\begin{array}{l}\text { No. } \\
\text { Patient }\end{array}$ & Gender & $\begin{array}{l}\text { Age, } \\
\text { Year }\end{array}$ & $\begin{array}{l}\text { time } \\
\text { interval }\end{array}$ & $\begin{array}{l}\text { No. } \\
\text { lesion }\end{array}$ & $\begin{array}{l}\text { Field } \\
\text { Strength }\end{array}$ & b value & Blind & $\begin{array}{l}\text { Reference } \\
\text { Standard }\end{array}$ & $\begin{array}{l}\text { ADC cut } \\
\text { off value } \\
\left(\times 10^{-3} \mathrm{~mm}^{2} / \mathrm{s}\right)\end{array}$ & $\begin{array}{l}\text { Threshold } \\
\text { used }\end{array}$ \\
\hline Afifi [9] & 2016 & Egypt & Pro & 20 & $18 / 2$ & $\begin{array}{l}56(42- \\
69)\end{array}$ & $3 w$ & 20 & $1.5 \mathrm{~T}$ & $0,300,600$ & NR & follow up & NR & Visual \\
\hline Du [10] & 2014 & China & $\operatorname{Re}$ & 89 & $57 / 32$ & $\begin{array}{l}56.0(26- \\
78)\end{array}$ & $1 \mathrm{mo}$ & 113 & $1.5 \mathrm{~T}$ & 0,800 & $N R$ & follow up & 1.54 & $A D C$ \\
\hline $\begin{array}{l}\text { Ebraheem } \\
\text { [11] }\end{array}$ & 2017 & Egypt & Pro & 50 & $42 / 8$ & $\begin{array}{l}60(40- \\
79)\end{array}$ & $N R$ & 50 & $1.5 \mathrm{~T}$ & $0,50,1000$ & $N R$ & follow up & NR & Visual \\
\hline $\begin{array}{l}\text { Goshima } \\
\text { [12] }\end{array}$ & 2008 & Japan & $\operatorname{Re}$ & 25 & $18 / 7$ & $\begin{array}{l}60(48- \\
79)\end{array}$ & $2-6 \mathrm{mo}$ & 39 & $1.5 \mathrm{~T}$ & 0,500 & Y & follow up & $N R$ & Visual \\
\hline $\begin{array}{l}\text { Hassan } \\
{[13]}\end{array}$ & 2019 & USA & $\mathrm{Re}$ & 60 & $45 / 15$ & $\begin{array}{l}60(40- \\
73)\end{array}$ & $N R$ & 63 & $1.5 \mathrm{~T}$ & $0,400,800$ & $N R$ & follow up & $N$ & Visual \\
\hline $\begin{array}{l}\text { Kokabi } \\
{[14]}\end{array}$ & 2015 & Georgia & Pro & 57 & $39 / 18$ & $\begin{array}{l}61.3(25- \\
82)\end{array}$ & $3 \mathrm{mo}$ & 57 & $1.5 \mathrm{~T}$ & $\begin{array}{l}50,400 \\
800\end{array}$ & $N R$ & follow up & 0.83 & $A D C$ \\
\hline Li [15] & 2016 & China & Pro & 117 & $86 / 31$ & $\begin{array}{l}51.7(31- \\
74)\end{array}$ & $1 \mathrm{mo}$ & 117 & $N R$ & NR & $N R$ & follow up & 1.24 & ADC \\
\hline $\begin{array}{l}\text { Mannelli } \\
{[16]}\end{array}$ & 2009 & USA & $\mathrm{Re}$ & 21 & $19 / 2$ & $\begin{array}{l}57.7(30- \\
70)\end{array}$ & $\begin{array}{l}10 \mathrm{~d}- \\
3 \mathrm{mo}\end{array}$ & 28 & $1.5 \mathrm{~T}$ & $0,50,500$ & Y & Patholoy & 2.16 & $A D C$ \\
\hline Wu [17] & 2017 & China & Pro & 84 & $57 / 27$ & $\begin{array}{l}54.5(25- \\
76)\end{array}$ & $\begin{array}{l}1 \mathrm{mo}- \\
2 \mathrm{mo}\end{array}$ & 84 & $1.5 \mathrm{~T}$ & $\begin{array}{l}300,600 \\
800\end{array}$ & $N R$ & follow up & 1.20 & ADC \\
\hline Xiao [18] & 2008 & China & $\mathrm{Re}$ & 15 & $13 / 2$ & $\begin{array}{l}45.7(17- \\
63)\end{array}$ & $\begin{array}{l}10 \mathrm{~d}- \\
2 \mathrm{mo}\end{array}$ & 30 & $1.5 \mathrm{~T}$ & 0,500 & Y & patholoy & NR & Visual \\
\hline $\begin{array}{l}\text { Yousef } \\
{[19]}\end{array}$ & 2017 & Egypt & Pro & 45 & $38 / 7$ & $\begin{array}{l}59(38- \\
75)\end{array}$ & $3 w-5 m$ & 59 & $1.5 \mathrm{~T}$ & $0,400,800$ & $N R$ & follow up & NR & Visual \\
\hline Yuan [20] & 2014 & China & Pro & 41 & $34 / 7$ & $\begin{array}{l}56.2(23- \\
78)\end{array}$ & $6 w-8 w$ & 52 & $1.5 \mathrm{~T}$ & 0,500 & Y & follow up & 1.84 & Visual \\
\hline
\end{tabular}

No Number, Pro Prospective, Re Retrospective, NR Not report, ADC Apparent diffusion coefficient

\section{Assessment of study quality}

The methodological assessment results of the included studies are shown in Table 2. The risk of bias for patient selection was primarily related to case-control studies. Case-control studies were defined as studies involving both patients prediagnosed with and patients without residual or recurrent HCCs after TACE before undergoing DWI examination. In this meta-analysis, none of the included studies had a case-control design, leading to a low risk of bias in patient selection for all included studies. For this meta-analysis, only four studies showed a clear blinding application method [12, 16, 18, 20], which results in an unclear risk of bias concerning the index test in the other eight studies. Pathology, DSA and clinical follow-up results are all reliable reference standards in diagnosing residual or recurrent HCCs after TACE; therefore, all studies included in this meta-analysis presented a low risk of bias compared with the reference standard.

\section{Statistical analysis}

\section{Heterogeneity test}

The Spearman correlation coefficient was $0.141 \quad(P=$ $0.662>0.05$ ), indicating that there was no obvious threshold effect of DWI in diagnosing residual or recurrent HCCs after TACE. The chi-squared value of the pooled SEN was $27.47(P=0.02<0.05)$, and the $I^{2}$ value was $49.03 \%$, demonstrating low heterogeneity for SEN. SPE had a chi-squared value of $56.58(P<0.01)$, and the $I^{2}$ value was $75.38 \%$, representing high heterogeneity.

\section{Pooled analysis}

The pooled weighted values of DWI in diagnosing residual or recurrent HCCs after TACE were as follows: $\mathrm{SEN}=85 \%$ (95\% CI: 74-92\%), SPE $=83 \%(95 \%$ CI: 75-88\%), PLR =5.12 (95\% CI: 3.27-7.38), NLR = 0.18 (95\% CI: $0.09-0.34$ ), and AUC $=0.90$ (95\% CI: 0.87-0.92). Forest plots and ROC curves for the 12 studies are shown in Figs. 2, 3, 4.

\section{Comparison of $A D C$ values}

Among the included studies, 8 studies compared the ADC value between residual or recurrent HCCs and necrotic tumors. Our pooled analysis demonstrated that residual or recurrent $\mathrm{HCCs}$ had significantly lower ADC values than necrotic tumors $(\mathrm{MD}=-0.48,95 \% \mathrm{CI}$ : 0.69 $-0.27, P<0.01$ ), which is shown in Fig. 5, indicating that the ADC value may be important for differentiating residual and recurrent HCCs after TACE. 
Table. 2 The distribution of included quality according to QUADAS-2 tool

\begin{tabular}{|c|c|c|c|c|c|c|c|c|c|c|c|c|}
\hline & $\begin{array}{l}\text { Afifi } \\
2016 \\
{[9]} \\
\end{array}$ & $\begin{array}{l}\mathrm{Du} \\
2014 \\
{[10]} \\
\end{array}$ & $\begin{array}{l}\text { Ebraheem } \\
2017 \text { [11] }\end{array}$ & $\begin{array}{l}\text { Goshima } \\
2008 \text { [12] }\end{array}$ & $\begin{array}{l}\text { Hassan } \\
2009[13]\end{array}$ & $\begin{array}{l}\text { Kokabi } \\
2015 \text { [14] }\end{array}$ & $\begin{array}{l}\text { Li } 2016 \\
{[15]}\end{array}$ & $\begin{array}{l}\text { Mannelli } \\
2009 \text { [16] }\end{array}$ & $\begin{array}{l}\text { Wu } \\
2017 \\
{[17]}\end{array}$ & $\begin{array}{l}\text { Xiao } \\
2008 \\
{[18]} \\
\end{array}$ & $\begin{array}{l}\text { Yousef } \\
2017 \text { [19] }\end{array}$ & $\begin{array}{l}\text { Yuan } \\
2014 \text { [20] }\end{array}$ \\
\hline Ris of bias & U & U & U & L & U & U & U & L & U & $L$ & U & $\mathrm{L}$ \\
\hline $\begin{array}{l}\text { Patient } \\
\text { selection }\end{array}$ & L & L & L & L & L & L & L & L & L & L & L & $L$ \\
\hline Index Test & U & U & U & L & U & U & U & L & U & L & U & $\mathrm{L}$ \\
\hline $\begin{array}{l}\text { Reference } \\
\text { standard }\end{array}$ & $L$ & L & L & $\mathrm{L}$ & L & L & L & L & L & L & L & $L$ \\
\hline $\begin{array}{l}\text { Flow and } \\
\text { timing }\end{array}$ & $L$ & L & L & L & L & L & L & L & L & L & L & $L$ \\
\hline $\begin{array}{l}\text { Applicability } \\
\text { Concerns }\end{array}$ & $L$ & L & L & L & L & L & L & L & L & L & L & $L$ \\
\hline $\begin{array}{l}\text { Patient } \\
\text { selection }\end{array}$ & $L$ & L & $L$ & L & $L$ & L & $L$ & L & L & L & L & $L$ \\
\hline Index Test & U & U & U & L & U & U & U & L & U & L & U & $\mathrm{L}$ \\
\hline $\begin{array}{l}\text { Reference } \\
\text { standard }\end{array}$ & $L$ & L & L & L & L & L & $L$ & L & L & L & L & $L$ \\
\hline
\end{tabular}

L Low, U Unclear

\section{Subgroup analysis}

As presented in Table 3, the study design type, b value and threshold method used did not significantly affect the ability of DWI to diagnose residual or recurrent HCCs after TACE.

\section{Analysis of sensitivity and publication bias}

For the use of DWI in the detection of residual or recurrent HCCs after TACE, the reliability and stability of this meta-analysis were assessed by removing one study with unclear field strength and the use of the $\mathrm{b}$ value. The resulting SEN was $87 \%$ (95\% CI 78-93\%), SPE was $83 \%$ (95\% CI 74-89\%) and AUC was 0.91 (95\% CI 0.88-
0.93), indicating that the effect values were still within the $95 \%$ CI of the original results, thus showing that the results were reliable and stable. Deeks' funnel plot is presented in Fig. 6 and demonstrates no obvious publication bias of DWI in the diagnosis of residual or recurrent HCCs after TACE $(P=0.206)$.

\section{Discussion}

Because of the potential severe complications and relatively high cost, pathology and digital subtraction angiography are not recommended as routine follow-up examinations for diagnosing residual or recurrent HCCs after TACE [24]. However, residual or recurrent HCCs

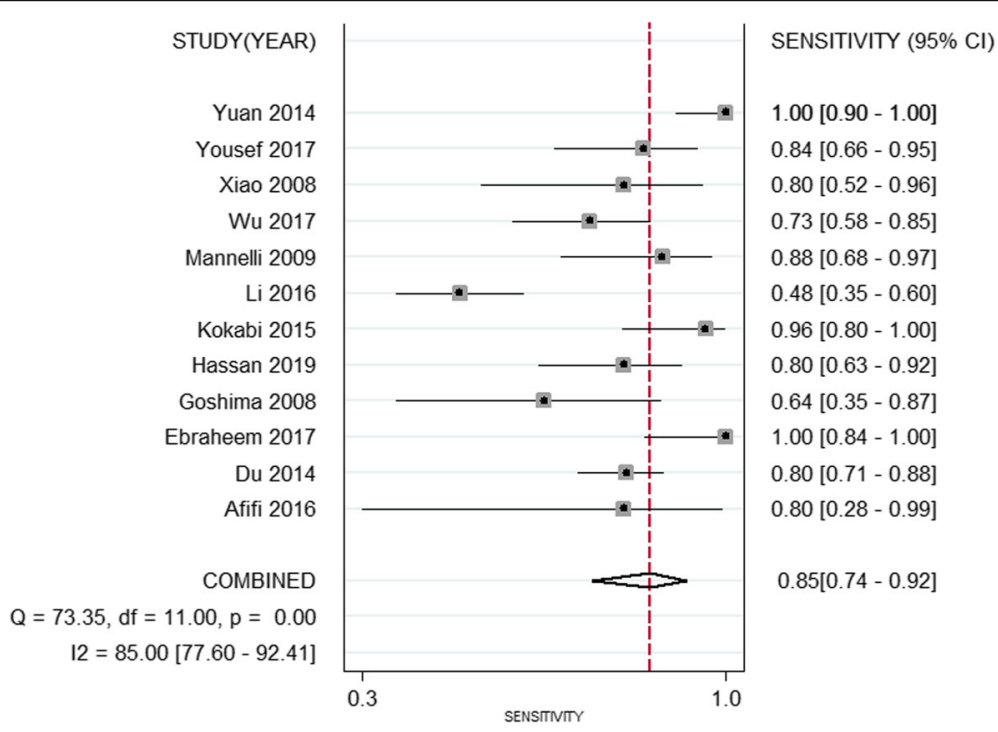

Fig. 2 Forest plots of sensitivity for DWI in diagnosing residual or recurrent HCCS after TACE 


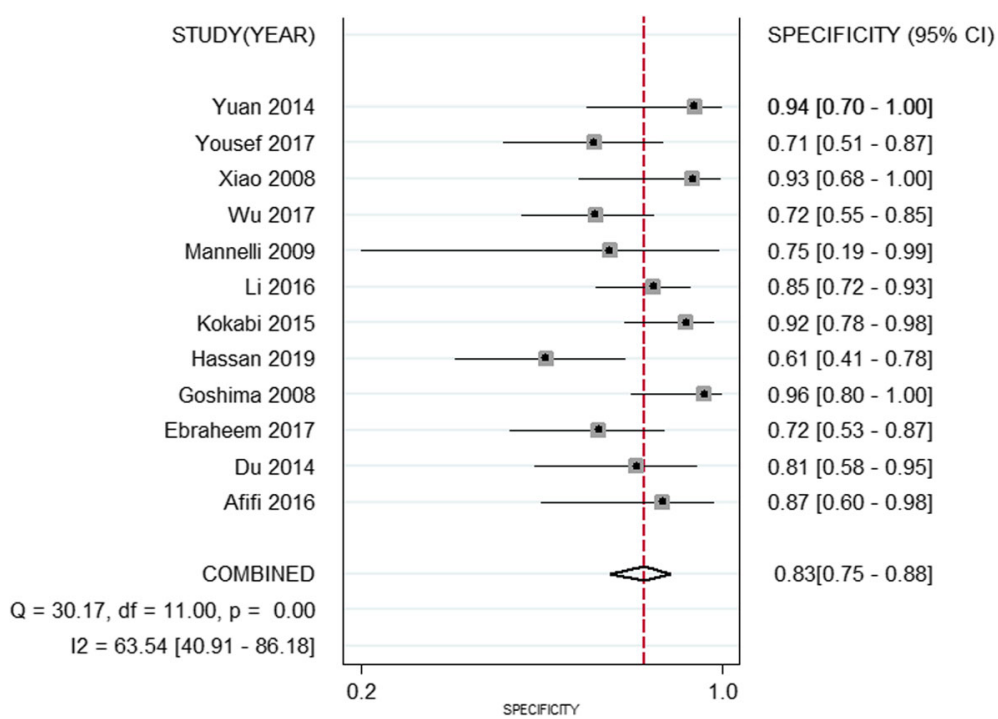

Fig. 3 Forest plots of specificity for DWI in the diagnosis of residual or recurrent HCCs after TACE

increase the disease burden and worsen the survival prognosis of patients after TACE [25]; thus, noninvasive imaging is increasingly being used to diagnose residual or recurrent HCCs after TACE. Contrast-enhanced computed tomography (CECT) is commonly used in analyzing the distribution of lipiodol deposition and is beneficial for evaluating the therapeutic effects of TACE [26]. However, lipiodol deposition often makes it hard to diagnose the residual tumor on CECT because the accumulation of intratumoral lipiodol may mask its enhancement, which would significantly decrease the accuracy and contribute to a lower sensitivity of $72 \%$ (95\% CI:

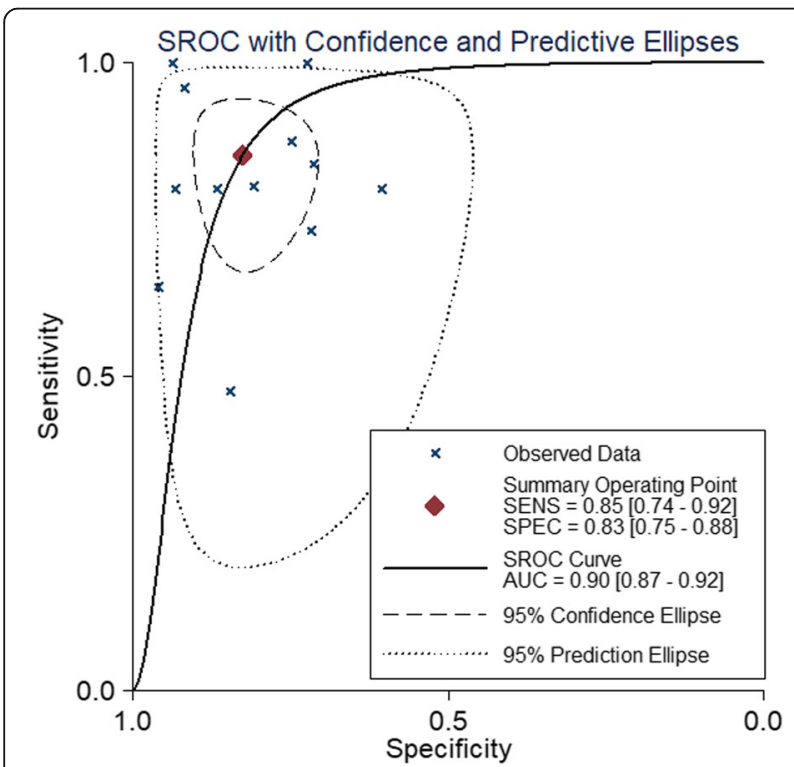

Fig. 4 Forest plots of ROC for DWI in the detection of residual or recurrent HCCS after TACE
67-76\%) [27] compared with this study conclusion that DWI had a higher sensitivity of $85 \%$ (95\% CI: $74-92 \%$ ) in detecting residual or recurrent HCCs. Contrastenhanced ultrasonography (CEUS) is a valuable imaging method for evaluating vascularity because the depiction of tumor vascularity is not affected by lipiodol accumulation. A recent meta-analysis reported that CEUS can reach up to a weighted SEN of 97\% (95\% CI: 95-99\%) in the diagnosis of residual or recurrent HCC after TACE [27]. Nevertheless, CEUS examination has always been conducted on a solitary mass or on a dominant mass in patients with multiple tumors, which limits its wide clinical application in detecting residual or recurrent $\mathrm{HCCs}$ after TACE [28].

After the TACE procedure, the HCC tumor cells undergo necrosis and apoptosis, with increased cell membrane permeability and enlarged cell gaps, leading to more water molecule movement on DWI and an increased ADC value. For residual or recurrent HCCs, the tortuosity of the extracellular space and the higher density of hydrophobic cellular membranes will increase cell density and restrict the apparent diffusion of water protons, thus presenting a high signal on DWI and a lower ADC value [7, 29]; therefore, DWI was increasingly used in the follow-up of TACE treatment. To provide a diagnostic value and to investigate the possible factors that affect the efficacy of conducting DWI, this meta-analysis was performed to evaluate the value of DWI in diagnosing residual or recurrent HCCs after TACE.

In this study, 12 studies comprising 624 patients and 712 tumors detected on DWI were included. The SEN, SPE, and AUC values of DWI in diagnosing residual or recurrent HCCs after TACE were 85\% (95\% CI: 74- 


\begin{tabular}{|c|c|c|c|c|c|c|c|c|c|c|}
\hline \multirow[b]{2}{*}{ Study or Subgroup } & \multicolumn{3}{|c|}{ residual + recurrent } & \multicolumn{3}{|c|}{ necrotic } & \multirow[b]{2}{*}{ Weight } & \multirow{2}{*}{$\begin{array}{l}\text { Mean Difference } \\
\text { IV. Random. } 95 \% \mathrm{CI}\end{array}$} & \multirow{2}{*}{\multicolumn{2}{|c|}{$\begin{array}{l}\text { Mean Difference } \\
\text { IV. Random, } 95 \% \mathrm{Cl}\end{array}$}} \\
\hline & Mean & SD & Total & Mean & SD & Total & & & & \\
\hline Du 2014 & 1.24 & 0.13 & 92 & 1.67 & 0.24 & 21 & $13.6 \%$ & $-0.43[-0.54,-0.32]$ & 1 & \\
\hline Kokabi 2015 & 1.05 & 0.2 & 25 & 1.65 & 0.31 & 37 & $13.4 \%$ & $-0.60[-0.73,-0.47]$ & & \\
\hline Li 2016 & 1.06 & 0.17 & 65 & 1.69 & 0.24 & 52 & $13.8 \%$ & $-0.63[-0.71,-0.55]$ & & \\
\hline Mannelli 2009 & 1.33 & 0.41 & 24 & 2.04 & 0.38 & 4 & $9.2 \%$ & $-0.71[-1.12,-0.30]$ & & \\
\hline Wu 2017 & 1.42 & 0.4 & 45 & 1.24 & 0.37 & 39 & $13.0 \%$ & $0.18[0.02,0.34]$ & 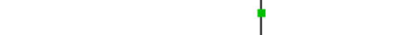 & \\
\hline Xiao 2008 & 1.42 & 0.16 & 15 & 1.58 & 0.18 & 15 & $13.4 \%$ & $-0.16[-0.28,-0.04]$ & T & \\
\hline Yousef 2017 & 1.2 & 0.1 & 28 & 2 & 0.9 & 31 & $10.7 \%$ & $-0.80[-1.12,-0.48]$ & & \\
\hline Yuan 2014 & 1.42 & 0.25 & 36 & 2.22 & 0.31 & 16 & $12.9 \%$ & $-0.80[-0.97,-0.63]$ & & \\
\hline Total $(95 \% \mathrm{Cl})$ & & & 330 & & & 215 & $100.0 \%$ & $-0.48[-0.69,-0.27]$ & & \\
\hline \multicolumn{9}{|c|}{$\begin{array}{l}\text { Heterogeneity: } \text { Tau }^{2}=0.08 ; \text { Chi }^{2}=125.18, d f=7(P \\
\text { Test for overall effect: } Z=4.43(P<0.00001)\end{array}$} & 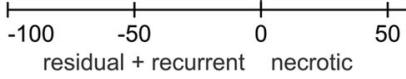 & 100 \\
\hline
\end{tabular}

92\%), 83\% (95\% CI: 75-88\%), and 0.90 (95\% CI: $0.87-$ 0.92), respectively, indicating a high value of DWI in diagnosing residual or recurrent HCCs after TACE. Additionally, the PLR for DWI was 5.12 (95\% CI: 3.277.38), revealing moderate accuracy in diagnosing residual or recurrent HCCs after TACE. The NLR value for DWI was 0.18 (95\% CI: 0.09-0.34), and a negative DWI result may be used as a moderate justification to rule out residual or recurrent HCCs after TACE. Moreover, this pooled analysis also indicated that the ADC value of necrotic tumors was significantly higher than that of residual or recurrent HCCs, confirming previous findings and revealing that the ADC value can be used as an efficient imaging method to differentiate the properties of lesions after TACE.

In this meta-analysis, the opposite results of falsenegative (1-SEN) and false-positive (1-SPE) rates were 15 and $17 \%$, respectively, for DWI in diagnosing residual or recurrent HCCs after TACE, and some of the following possible factors could contribute to the relatively high number of false-negative and false-positive results. 1) Adjacent hepatic inflammation could restrict water diffusion, resulting in sustained hyperintensity on DWI, thereby producing a false-positive DWI diagnosis of the lesion after TACE [30, 31]. 2) Intralesional hemorrhage or liquefactive necrosis can occur after TACE, which may also contribute to diffusion restriction in necrotic tumors, and can decrease the accuracy of DWI in the detection of residual or recurrent HCCs [32]. 3) Owing to the limited spatial resolution of DWI, small tumors would not be diagnosed precisely, leading to falsenegative and false-positive results on DWI [33]. 4) The signal intensities observed on DWI are easily affected by the T2-relaxation time of the tissue, as seen in the fact that a false-positive diagnosis of necrotic tissue may be induced by well-differentiated HCCs, high-grade dysplastic nodules, and hemangioma [34]. Only histopathology can be regarded as the absolute gold standard for diagnosing residual or recurrent HCCs [22]. DSA or follow-up results may contribute to false-positive results.

Significant sources of heterogeneity concerning the use of DWI in the diagnosis of residual or recurrent HCCs after TACE and the evaluation of this metaanalysis demonstrated 4 potential factors that may account for this result: 1) Freiman et al. [35] reported that a higher $b$ value might decrease the signal-to-noise

Table 3 Subgroup analysis for the diagnostic performance of DWI on overall level

\begin{tabular}{|c|c|c|c|c|c|c|}
\hline Characteristic & No.of Studies & $\begin{array}{l}\text { Sensitivity } \\
(95 \% \mathrm{Cl})\end{array}$ & $\begin{array}{l}\text { Specificity } \\
(95 \% \mathrm{Cl})\end{array}$ & $\begin{array}{l}P^{2} \text { index of Sensitivity/ } \\
\text { Specificity }\end{array}$ & AUC $(95 \% \mathrm{Cl})$ & $P$ Value \\
\hline All studies & 12 & $0.85(0.74-0.92)$ & $0.83(0.75-0.88)$ & $85.0 / 65.3$ & $0.90(0.87-0.92)$ & \\
\hline \multicolumn{7}{|l|}{ Study design } \\
\hline Retrospective & 5 & $0.80(0.73-0.86)$ & $0.81(0.71-0.88)$ & $0.00 / 69.6$ & $0.86(0.83-0.89)$ & \multirow[t]{2}{*}{0.68} \\
\hline Prospective & 7 & $0.91(0.69-0.98)$ & $0.82(0.74-0.88)$ & $92.1 / 67.5$ & $0.88(0.85-0.90)$ & \\
\hline \multicolumn{7}{|l|}{ b value } \\
\hline$<800$ & 5 & $0.88(0.69-0.96)$ & $0.92(0.83-0.96)$ & $67.5 / 0.00$ & $0.93(0.91-0.95)$ & \multirow[t]{2}{*}{0.40} \\
\hline$\geq 800$ & 6 & $0.85(0.75-0.92)$ & $0.76(0.66-0.83)$ & $58.8 / 49.2$ & $0.87(0.83-0.89)$ & \\
\hline \multicolumn{7}{|c|}{ Threshold method } \\
\hline visual & 6 & $0.82(0.71-0.89)$ & $0.82(0.67-0.91)$ & 38.663 .1 & $0.88(0.85-0.90)$ & \multirow[t]{2}{*}{0.47} \\
\hline ADC & 6 & $0.87(0.65-0.96)$ & $0.85(0.76-0.91)$ & $92.9 / 72.7$ & $0.90(0.87-0.92)$ & \\
\hline
\end{tabular}

$P$ value: Comparasion of AUC value between different subgroup analyses 


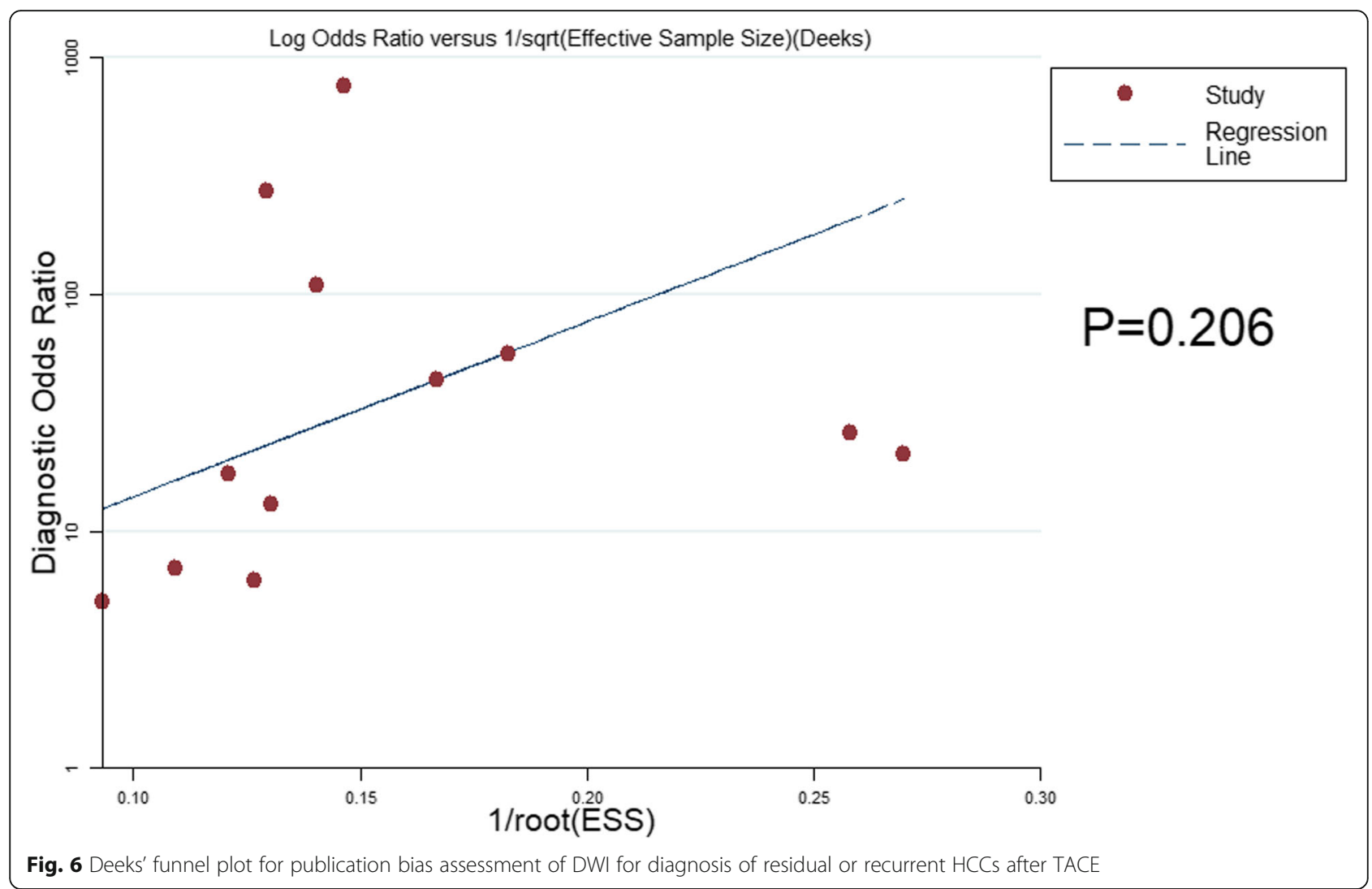

ratio (SNR), whereas blood perfusion can be easily affected by a lower b value. Vandecaveye et al. [36] suggested that the SNR is the highest and the image quality of DWI is the best at a specific b value of $600 \mathrm{~s} / \mathrm{mm}^{2}$. This meta-analysis demonstrated that DWI performed better for the diagnosis of residual or recurrent HCCs after TACE with lower $b$ values than with higher $b$ values, revealing that the $b$ value of DWI was one of the factors affecting diagnostic efficacy. 2) Heterogeneity might be induced by the different threshold methods used. There is a trend towards a higher diagnostic value of ADC measurement compared to visual diagnosis. Visual diagnosis is easily affected by the T2 shine-through effect and may account for this result [37]. 3) There are 5 retrospective studies and 7 prospective studies included in this study, which may be another reason for the heterogeneity. Prospective studies tended to perform better, although these findings were not statistically significant. 4) Heterogeneity might also be induced by the various field strengths adopted in the different studies [38], because a higher resolution of images will be created with higher field DWI-MRI scanners. However, we were not able to perform subgroup analysis associated with field strength owing to the limited included studies.

There were some deficiencies in this study that should be noted. First, although a combination of electronic and manual searches was performed, only 12 studies comprising
624 patients on DWI were involved. The small number of included studies might have a negative impact on the diagnostic accuracy; therefore, further high-quality studies on a larger scale may be required. Second, the exclusion of studies other than those published in English, review articles and conference abstracts may contribute to potential publication bias. Third, field strength was found to affect the efficacy of DWI in diagnosing residual or recurrent HCCs after TACE. However, because of the limitations of the included studies, the accuracy of DWI in diagnosing residual or recurrent HCCs after TACE from the perspective of field strength was not been explored.

\section{Conclusion}

In conclusion, our study suggested that DWI performs well in diagnosing residual or recurrent HCCs after TACE, and the ADC value may serve as an alternative marker in the further evaluation of HCC patients after TACE.

\section{Abbreviation}

ADC: Apparent diffusion coefficient; AUC: Area under the curve;

$\mathrm{Cl}$ : Confidence interval; DSA: Digital subtraction angiography; DWI: Diffusion weighted imaging; FN: False negative; FP: False positive; HCC: Hepatocellular carcinoma; MD: Mean difference; ROC: Receiver operator characteristics;

TACE: Transarterial chemoembolization; TN: True negative; TP: True positive

Acknowledgements

Not applicable. 


\section{Authors' contributions}

$\mathrm{ZL}$ and HFL conceived the study, searched databases, selected studies, extracted data. ZL and JMF wrote the draft of the manuscript. CH and ZFL provided advice on meta-analysis methodology, analyzed the data. YSX and ZL reviewed and revised the manuscript. HFL and JQL helped search databases, selected studies, selected studies, extracted and analyzed data, and contributed to writing the manuscript. All authors read and approved the final manuscript.

\section{Funding}

This work was supported by the Fundamental Research Funds for the Central Universities (Izujbky-2019-cd04); National Natural Science Foundation of China (81960323).

\section{Availability of data and materials}

The datasets used and/or analyzed during the current study are available from the corresponding author on reasonable request.

\section{Ethics approval and consent to participate}

Not applicable.

\section{Consent for publication}

Not applicable.

\section{Competing interests}

The authors declare that they have no competing interests.

\section{Author details}

'The first Clinical Medical College of Lanzhou University, Lanzhou 730000, Gansu, China. ${ }^{2}$ First Hospital of Lanzhou University, Lanzhou 730000, Gansu, China. ${ }^{3}$ Department of Radiology, Third Affiliated Hospital of Soochow University \& Changzhou First People's Hospital, No.185, Juqian Street, Tianning District, Changzhou 213003, Jiangsu, China.

\section{Received: 9 October 2019 Accepted: 29 December 2019}

\section{Published online: 06 January 2020}

\section{References}

1. Bray F, Ferlay J, Soerjomataram I, et al. Global cancer statistics 2018: GLOBOCAN estimates of incidence and mortality worldwide for 36 cancers in 185 countries. CA. 2018;68(6):394-424.

2. Forner A, Reig M, Bruix J. Hepatocellular carcinoma. Lancet. 2018;391(10127): 1301-14.

3. Moris D, Chakedis J, Sun SH, et al. Management, outcomes, and prognostic factors of ruptured hepatocellular carcinoma: a systematic review. J Surg Oncol. 2018:117(3):341-53.

4. Sapisochin G, Barry A, Doherty M, et al. Stereotactic body radiotherapy vs. TACE or RFA as a bridge to transplant in patients with hepatocellular carcinoma. An intention-to-treat analysis. J Hepatol. 2017;67(1):92-9.

5. Sieghart W, Hucke F, Peck-Radosavljevic M. Transarterial chemoembolization: modalities, indication, and patient selection. J Hepatol. 2015;62(5):1187-95.

6. Cheng HY, Wang X, Chen D, et al. The value and limitation of transcatheter arterial chemoembolization in preventing recurrence of resected hepatocellular carcinoma. World J Gastroenterol. 2005;11(23):3644-6.

7. Chapiro J, Wood LD, Lin M, et al. Radiologic-pathologic analysis of contrastenhanced and diffusion-weighted MR imaging in patients with HCC after TACE: diagnostic accuracy of 3D quantitative image analysis. Radiology. 2014;273(3):746-58.

8. Taron J, Johannink J, Bitzer M, et al. Added value of diffusion-weighted imaging in hepatic tumors and its impact on patient management. Cancer Imaging. 2018;18(1):10

9. Afifi AH, Naguib AM, Seragaldin F. Diffusion weighted magnetic resonance imaging in assessment of hepatocellular carcinoma after chemoembolization. Egypt J Radiol Nucl Med. 2016;47(1):61-71.

10. Du K, Yang K, Yin J, et al. Response to transcatheter arterial chemoembolization in hepatocellular carcinoma using apparent diffusion coefficient. Chin J Med Imaging. 2014;22(5):365-8.

11. Ebeed $A E$, Romeih MAE-h, Refat MM, et al. Role of dynamic contrastenhanced and diffusion weighted MRI in evaluation of hepatocellular carcinoma after chemoembolization. Egypt J Radiol Nucl Med. 2017;48(4): 807-15.
12. Goshima S, Kanematsu M, Kondo $\mathrm{H}$, et al. Evaluating local hepatocellula carcinoma recurrence post-transcatheter arterial chemoembolization: is diffusion-weighted MRI reliable as an indicator? J Magn Reson Imaging. 2008;27(4):834-9.

13. Hassan AE, Mostafa RE, Nada A, et al. Diagnostic accuracy of intermediate bvalue diffusion-weighted imaging for detection of residual hepatocellular carcinoma following transarterial chemoembolization with drug-eluting beads. Indian J Radio Imaging. 2019;29(2):195-200.

14. Kokabi N, Ludwig JM, Camacho JC, et al. Baseline and early MR apparent diffusion coefficient quantification as a predictor of response of unresectable hepatocellular carcinoma to doxorubicin drug-eluting bead chemoembolization. J Vasc Interv Radiol. 2015;26(12):1777-86.

15. Li Z, Xue TQ, Chen XY. Predictive values of serum VEGF and CRP levels combined with contrast enhanced MRI in hepatocellular carcinoma patients after TACE. Am J Cancer Res. 2016;6(10):2375-85.

16. Mannelli L, Kim S, Hajdu CH, et al. Serial diffusion-weighted MRI in patients with hepatocellular carcinoma: prediction and assessment of response to transarterial chemoembolization. Preliminary experience. Eur J Radiol. 2013; 82(4):577-82.

17. Wu XM, Wang JF, Ji JS, et al. Evaluation of efficacy of transcatheter arterial chemoembolization for hepatocellular carcinoma using magnetic resonance diffusion-weighted imaging. Onco Targets Ther. 2017;10:1637-43.

18. Xiao YP, Xiao EH, Luo JG, et al. Comparison between pathological findings and MR diffusion-weighted imaging in primary hepatocellular carcinoma after transcatheter arterial chemoembolization. Chin J Oncol. 2008;30(12): 914-6.

19. Yousef MI, Refaat MM, Faheem MH. Role of diffusion-weighted magnetic resonance imaging in the evaluation of hepatocellular carcinoma response to transcatheter arterial chemoembolization using drug eluting beads; correlation with dynamic MRI. Egypt J Radiol Nucl Med. 2017:48(4):817-24.

20. Yuan Z, Li WT, Ye XD, et al. Utility of diffusion-weighted imaging to assess hepatocellular carcinoma viability following transarterial chemoembolization. Oncol Lett. 2014;8(2):831-6.

21. Hutton B, Salanti G, Caldwell DM, et al. The PRISMA extension statement for reporting of systematic reviews incorporating network meta-analyses of health care interventions: checklist and explanations. Ann Intern Med. 2015; 162(11):777-84

22. Jeon MY, Lee HW, et al. Reproducibility of European association for the study of the liver criteria and modified response evaluation criteria in solid tumors in patients treated with sorafenib. Liver Int. 2018;38(9):1655-63.

23. Whiting PF, Rutjes AW, Westwood ME, et al. QUADAS-2: a revised tool for the quality assessment of diagnostic accuracy studies. Ann Intern Med. 2011:155(8):529-36.

24. Yang $K$, Zhang $X M$, Yang $L$, et al. Advanced imaging techniques in the therapeutic response of transarterial chemoembolization for hepatocellular carcinoma. World J Gastroenterol. 2016;22(20):4835-47.

25. Young $S$, Craig $P$, Golzarian J. Current trends in the treatment of hepatocellular carcinoma with transarterial embolization: a cross-sectional survey of techniques. Eur Radiol. 2019:29(6):3287-95.

26. Paul SB, Dhamija E, Gamanagatti SR, et al. Evaluation of tumor response to intra-arterial chemoembolization of hepatocellular carcinoma: comparison of contrast-enhanced ultrasound with multiphase computed tomography. Diagn Interv Imaging. 2017:98(3):253-60.

27. Zhong J, Su Z, Zhang Y, et al. Contrast-enhanced ultrasonography versus contrast-enhanced computed tomography for assessment of residual tumor from hepatocellular carcinoma treated with transarterial chemoembolization: a meta-analysis. J Ultrasound. 2018;37(8):1881-90.

28. Takizawa K, Numata K, Morimoto M, et al. Use of contrast-enhanced ultrasonography with a perflubutane-based contrast agent performed one day after transarterial chemoembolization for the early assessment of residual viable hepatocellular carcinoma. Eur J Radiol. 2013;82(9):1471-80.

29. Yuan Z, Ye XD, Dong $S$, et al. Role of magnetic resonance diffusionweighted imaging in evaluating response after chemoembolization of hepatocellular carcinoma. Eur J Radiol. 2010:75(1):e9-14.

30. Hwang SH, Yu JS, Chung J, et al. Transient hepatic attenuation difference (THAD) following transcatheter arterial chemoembolization for hepatic malignancy: changes on serial CT examinations. Eur Radiol. 2008;18(8): 1596-603.

31. Shinya S, Sasaki T, Nakagawa Y, et al. Acute pancreatitis successfully diagnosed by diffusion-weighted imaging: a case report. World J Gastroenterol. 2008;14(35):5478-80. 
32. Tung GA, Evangelista P, Rogg JM, et al. Diffusion-weighted MR imaging of rim-enhancing brain masses: is markedly decreased water diffusion specific for brain abscess? Am J Roentgenol. 2001;177(3):709-12.

33. Andre JB, Zaharchuk G, Fischbein NJ, et al. Clinical assessment of standard and generalized autocalibrating partially parallel acquisition diffusion imaging: effects of reduction factor and spatial resolution. Am J Neuroradiol. 2012;33(7):1337-42.

34. Duran $\mathrm{R}$, Ronot $\mathrm{M}$, Kerbaol A, et al. Hepatic hemangiomas: factors associated with T2 shine-through effect on diffusion-weighted MR sequences. Eur J Radiol. 2014;83(3):468-78.

35. Freiman M, Voss SD, Mulkern RV, et al. In vivo assessment of optimal bvalue range for perfusion-insensitive apparent diffusion coefficient imaging. Med Phys. 2012;39(8):4832-9.

36. Vandecaveye V, De Keyzer F, Verslype C, et al. Diffusion-weighted MRI provides additional value to conventional dynamic contrast-enhanced MR for detection of hepatocellular carcinoma. Eur Radiol. 2009;19(10):2456-66.

37. Taouli B, Vilgrain V, Dumont $E$, et al. Evaluation of liver diffusion isotropy and characterization of focal hepatic lesions with two single-shot echoplanar MR imaging sequences: prospective study in 66 patients. Radiology. 2003;226(1):71-8,

38. Eshed I, Krabbe S, Ostergaard M, et al. Influence of field strength, coil type and image resolution on assessment of synovitis by unenhanced MRI--a comparison with contrast-enhanced MRI. Eur Radiol. 2015;25(4):1059-67.

\section{Publisher's Note}

Springer Nature remains neutral with regard to jurisdictional claims in published maps and institutional affiliations.

Ready to submit your research? Choose BMC and benefit from:

- fast, convenient online submission

- thorough peer review by experienced researchers in your field

- rapid publication on acceptance

- support for research data, including large and complex data types

- gold Open Access which fosters wider collaboration and increased citations

- maximum visibility for your research: over $100 \mathrm{M}$ website views per year

At $\mathrm{BMC}$, research is always in progress.

Learn more biomedcentral.com/submissions 